\title{
Ethnographic Decision Tree Modeling of the Decision Criteria and Decision Patterns for Adult Married Women with Unexpected Pregnancies
}

\author{
Yu-Chan Li ${ }^{1}$, Yieh Loong Tsai ${ }^{2}$, Pei-Jung Lan ${ }^{1}$ \\ ${ }^{1}$ Department of Thanatology and Health Counseling, College of Human Development and Health, National Taipei \\ University of Nursing and Health Sciences, Taiwan \\ ${ }^{2}$ Department of Obstetrics \& Gynecology, Shin Kong Wu Ho-Su Memorial Hospital, Taiwan \\ Email:m002044@ms.sks.org.tw, yuhchain@ntunhs.edu.tw
}

How to cite this paper: Li, Y.-C., Tsai, Y.L. and Lan, P.-J. (2017) Ethnographic Decision Tree Modeling of the Decision Criteria and Decision Patterns for Adult Married Women with Unexpected Pregnancies. Open Journal of Obstetrics and Gynecology, 7, 1052-1063.

https://doi.org/10.4236/ojog.2017.710106

Received: August 15, 2017

Accepted: October 8, 2017

Published: October 11, 2017

Copyright (c) 2017 by authors and Scientific Research Publishing Inc. This work is licensed under the Creative Commons Attribution International License (CC BY 4.0).

http://creativecommons.org/licenses/by/4.0/

\begin{abstract}
Introduction: As far as adult and married women were concerned, when they occurred to "unplanned pregnancy", they felt so surprised and concussive all the time. Besides, the unplanned pregnancy also affects the other members in the family system. Therefore, when married women have to face the choice: "birth" or "abortion", they'll consider lots of thoughts and different decision criteria and decision pattern under various influences on physician, mind, mental and society. The purpose of this study was to investigate the criteria considered and the decision patterns involved when adult married women decide whether to terminate or continue an unplanned pregnancy. Methods: The study uses the method- "Ethnographic Decision Tree Modeling" [1] to build model of the decision criteria and decision patterns involved when adult married women make a decision about their unplanned pregnancy. There are three process in the research method: "Pilot Study"-interview two groups, every group distinct 4 married adult women with unplanned pregnancies, which decide whether to terminate or continue an unplanned pregnancy, what is the items of decision characters affect to the choice: "birth" or "abortion". "Building of the Model", displays the importance in proper order of those items and build the modeling with these two groups of women. "Testing of the Model": investigate the criteria considered and the decision patterns involved when adult married women decide whether to terminate or continue an unplanned pregnancy. The study interviewed 34 married adult women with 43 unplanned pregnancies totally. Results: The result of the study finds out 12 items of decision characters, including planning to get pregnant or not,
\end{abstract}


stability of feelings for married partner, the points of view on life, was affected by mother, mother-in-law, an husband's emphasis on male, the meanings of children, the financial burden, the plan an assignment of career and time, the past pregnant experiences, the status of raising children, the health of parents and fetus, the effect of living environment, and social and cultural vision. Besides, there are four decision patterns of married adult women with unplanned pregnancy are "receiving abortion positively"; "giving birth as long as getting pregnancy naturally"; " the minds are hesitative and changeable", and "being forced by important others." Conclusion: By setting the decision model tree, we found several decision criteria and patterns, and possible modes actions to be taken, could offer to see the adult married women's decision-making and struggles in mind about unplanned pregnancy.

\section{Keywords}

Ethnographic Decision Tree Modeling, Adult and Married Women, Unplanned Pregnancy, Decision Pattern

\section{Introduction}

Pregnancy is ranked the sixth major cause of everyday stress, particularly unplanned pregnancy [2]. There is no small proportion of adult married women with unplanned pregnancies facing the dilemma of continued pregnancy or induced abortion. For example, unplanned pregnancies in the United States have been observed in a third of teenage women and in two thirds of women aged 20 years or older [3]; and 50\% of pregnancies in the United States were unplanned [4]. By contrast, $30 \%$ of pregnancies among adult married women in Taiwan were unexpected (Liberty Times Net). Pregnancy is unplanned if either partner is not psychologically prepared at the time of learning of the pregnancy, regardless whether the pregnancy resulted from contraceptive failure or from not using contraception. To prevent such a predicament, family planning at an appropriately early time must be performed for an adult married couple; it involves consideration of whether or not to become pregnant, when to have children, number of births, interval between births and postnatal care. It also impacts the birth rights, sexual autonomy, and overall health status of adult married women, and requires consideration of physical, mental, spiritual, and social aspects for purposes of planning and decision [5].

A population policy was promulgated in Taiwan in the 1950s. The 3321 Family Planning Program was aimed at encouraging the first pregnancy in the third year of marriage, and a second pregnancy after another three years. Two children per family were considered just right, and boys and girls were considered equally good [6]. And now, in 2017, the birth rate in Taiwan has declined considerably, with couples giving birth to 1.1 children on average. Taking into consideration factors such as their family budgets, household chores, childcare, and 
emotional and marital conditions, most married couples typically practice birth control or even decide to have no children at all. One of their solutions to unplanned pregnancy is contraception, even induced abortion [7]. In Taiwan, over $25 \%$ of married women have undergone induced abortion at least once [8]; and deeper investigation shows that on average, one out of every four adult married women has experienced an induced abortion following unplanned pregnancy during their marriage. Therefore, factors such as the relationship with the partner, sex and marriage, sex and power, and other related factors are all worthy of consideration when deciding whether to continue or terminate a pregnancy [9].

Induced abortion has been long considered a secret that cannot be told. Stigmatized women may remain silent regarding unplanned pregnancy and induced abortion, which is why many adult married women with unplanned pregnancies may have to make decisions, and bear the consequences of those decisions, alone. Under pressure from the continuing growth of the fetus, they must make a hurried decision, without the fullness of time for detailed consideration. In addition, their decisions regarding the unplanned pregnancy, namely whether to continue or terminate the pregnancy, may be influenced by familial or socio-cultural pressures. Therefore, in hopes that prior to deciding to undergo induced abortion, adult married women can be given access to a comprehensive set of decision-making criteria and the chance to contemplate their values regarding family planning, the present study adopted the ethnographic decision tree modeling research method [1] to elucidate the decision criteria and decision patterns involved when adult married women make a decision about their unplanned pregnancy-that is, whether to continue a pregnancy or to terminate it. The results can shed light upon the decision-making process in such difficult times, particularly regarding the characteristics of the modes of thinking and the patterns these women demonstrate in their different decision-making behaviors. In other words, the purpose of this study was to investigate the criteria considered and the decision patterns involved when adult married women decide whether to terminate or continue an unplanned pregnancy. The findings of this study can provide useful reference information, such as decision criteria, pathways, and possible modes actions to be taken, for women in the same situation.

\section{Research Methods}

\section{1) Ethnographic Decision Tree Modeling}

Gladwin [1] proposed the ethnographic decision tree modeling method, which is a decision making approach involving organization, analysis, and prediction based on collected data. The method is based on decision trees, which originated from decision theory, and which are also called decision tree learning. It is a method of categorical data mining with regard to research materials of interest. The overall tree-like structure that can be derived from the three parts resembles a "tree structure" decision tree: 1) Initially choosing alternatives to draw out desires and directions of a choice; 2) Establishing branches to form multiple decision criteria; and 3) Linking paths that lead to final decisions (i.e., outcomes). 
For this study, we acted as qualitative ethnographic "insiders". We collected participant information and organized the decision criteria, thus establishing a decision tree, and revealing the formation of these criteria and the meanings that they represent. The results can be used by later quantitative research as a way to cross-check the degree of saturation and prediction accuracy of a decision tree model [10], and thus predict the probabilities that each decision criterion and final outcome will occur. Additionally, we conducted ethnographic qualitative interviews with adult married women facing unplanned pregnancies, regarding their various decision criteria, each of which was employed as a path node for consideration in a decision. For example, the criterion of whether the pregnancy was a planned one was used as one of the path nodes. After answering "yes" or "no", participants then proceeded to the next criterion. Following this, the overall decision tree-a logical thought structure established from the various criteria, resembling a tree-reveals the criteria and different decision modes, in their various layers and organized in a tree-like structure, of married women, from first learning of the unplanned pregnancy, to finally deciding whether to continue or terminate the pregnancy.

2) Research Participants

We recruited 34 Taiwanese adult married women, at least 20 years of age and with unplanned pregnancies, as the research participants during 2006-2007. There were three stages to this study's decision tree modeling process: 1) Pilot study: We interviewed four adult married women who had decided to continue their pregnancies and four who had decided to terminate pregnancy; the interviews discussed factors they took into consideration during the decision-making. The interview results were used to formulate multiple decision criteria, and from this, the prototype of the decision tree was developed. 2) Model building: The decision criteria were ranked according to the frequency with which the majority considered them, and the importance that they attached to them. This established a path model. Subsequently, the path model was adjusted by verifying whether each criterion on the decision tree was consistent with the experiences of four other participants who had decided to continue their pregnancies and four who had decided to terminate their pregnancies. 3) Model testing: We then found eighteen adult married women confronting unplanned pregnancies, to verify and analyze the accuracy of the decision criteria on the established decision tree. Finally, 34 married women shared their experiences over 43 pregnancies, providing a reference for the establishment of decision criteria and patterns for this study. Consider to protect their privacy and informed consent, all participants of this study have previously signed a consent form before interview, and to know our purpose, process and ethical clearance of this study.

\section{Results}

1) Decision Criteria and Characteristics

By using the aforementioned three-stage ethnographic decision tree modeling 
method, we obtained 31 decision criteria, forming decision nodes on the decision tree. We divided them into twelve major categories of decision characteristics, including: whether the pregnancy was planned or not; stability of feelings for marriage/partner; views regarding fetal life; consideration of mother-in-law, mother or husband's views regarding gender role effects on carrying on the ancestral line; significance of the number of children, gender, and appearance; economic burden; work, career and time management; impressions and influence of previous pregnancies; child parenting status; physical health status of parents and fetus; re-allocation of the living environment; and the opinions of the broader society and culture. These aspects exert different degrees of influence on the decisions adult married women make with regard to unplanned pregnancies. Table 1 shows the ranking of each decision criterion according to its level of importance and influence.

a) Planned/unplanned pregnancy is the key influencing decision criterion

The participants were only happy and expectant of a pregnancy if it was planned; otherwise, they tended to fall into dilemmas, caught between feelings of surprise and helplessness.

b) Partial influence of stability of feelings for married partner

The results indicated that $88 \%$ of the married women had a discussion with their husband before making a decision about unplanned pregnancy; however, the husbands' opinions did not necessarily become a determining criterion. Women tend to feel at ease when their decision is respected and supported by their husband. But when opinions differ, these women are often forced to go along with their husbands' thinking for the sake of their marriage and family; this will result in a mix of sadness and anger, and in some cases even thoughts of divorcing their husband. Nevertheless, when a woman has made up her mind, regardless of her husband's opinion, the marital relationship is affected; in silence, she bears the struggle and sorrow inside. Additionally, $12 \%$ of the participants did not discuss their decision with the husband, and $80 \%$ of them decided to receive induced abortion, either because they had reached a decision with their husband to get a divorce, or feel that the right to decide whether to give birth or not should be their own. Furthermore, $20 \%$ of the participants who decided to continue their pregnancy did so largely because they thought "I'm married, so I might as well", excepting when their husband had had an affair; in this case, they were inclined to terminate the pregnancy.

c) Views on fetal life

The participants had negative views toward concepts of life and induced abortion. Sincere religious beliefs, in particular, added to their apprehension and sense of guilt, thus influencing their decisions; most of these participants felt guilty about abortion, because their religion does not support induced abortion. Even those without religious beliefs thought that induced abortion is an act of killing, which influenced their decisions through fear of being sanctioned. Several participants felt that children are innocent and they have the right to live, or felt that the child was with them for life, and so decided to have the child. 
Table 1. Decision criteria $(\mathrm{N}=31)$.

\begin{tabular}{|c|c|c|}
\hline Decision Criteria (ranked in order of priority) & & Decision Characteristics \\
\hline $\begin{array}{l}\text { 1) Is this pregnancy unplanned? } \\
\text { 2) Did you think about not having the child when you first learned of your pregnancy? }\end{array}$ & A. (2) & Planned or unplanned pregnancy \\
\hline $\begin{array}{l}\text { 3) Did your husband have an affair, or have you had arguments or considered divorce? } \\
\text { 16) Does your husband not support having another child? } \\
\text { 29) Do you not think that "getting married and having kids" is natural? }\end{array}$ & B. (3) & $\begin{array}{l}\text { Stability of feelings } \\
\text { for married partner }\end{array}$ \\
\hline $\begin{array}{l}\text { 4) Are you unaffected by religious beliefs? } \\
\text { 19) Are you relatively able to accept issues of life and death? } \\
\text { 21) Do you think that a fetus is not a living thing? } \\
\text { 22) Do you feel that having this child was not meant to be? } \\
\text { 30) Do you feel that this child is innocent? } \\
\text { 27) When you realized that the baby survived even after you had } \\
\text { taken a morning-after pill, did you still think that the baby was not meant to be? }\end{array}$ & C. (6) & Views on fetal life \\
\hline $\begin{array}{l}\text { 6) Is your mother-in-law/mother satisfied with the gender (s) of the child (ren) } \\
\text { you've given birth to? } \\
\text { 31) Is your husband satisfied with the gender (s) of the child (ren) you've given birth to? }\end{array}$ & D. (2) & $\begin{array}{l}\text { Consideration of mother-in-law, } \\
\text { mother or husband's views } \\
\text { regarding gender role effects on } \\
\text { carrying on the ancestral line }\end{array}$ \\
\hline $\begin{array}{l}\text { 5) Are you satisfied with the gender (s) of the child (ren)you've given birth to? } \\
\text { 7) Are you satisfied with the number of children you've given birth to? } \\
\text { 14) Do you not wish to know what your child would look like? } \\
\text { 20) Do you not wish to give your existing child (ren) a sibling? } \\
\text { 17) Are you unaffected by whether or not the fetus is a boy? }\end{array}$ & E. (5) & $\begin{array}{l}\text { Significance of number } \\
\text { of children, gender, } \\
\text { and appearance }\end{array}$ \\
\hline 9) Do you have any economic burdens? & F. (1) & Economic Burden \\
\hline 8) Does your work occupy most of your time? & G. (1) & $\begin{array}{l}\text { Work, career, and } \\
\text { time management }\end{array}$ \\
\hline $\begin{array}{l}\text { 10) Are you unaffected by your own or other people's experiences with induced abortion? } \\
\text { 24) Is it too soon since your last pregnancy? }\end{array}$ & H. (2) & $\begin{array}{l}\text { Impression of and influence by } \\
\text { previous pregnancies }\end{array}$ \\
\hline $\begin{array}{l}\text { 11) Will rearing a child put a burden on your physical health, strength, and mentality? } \\
\text { 18) Are you concerned about being old when your children are still young in the future? } \\
\text { 26) Have you not given thought to your child's parenting problems in the future? } \\
\text { 25) Do you feel lonely from carrying a child, giving birth, and caring for the child alone? }\end{array}$ & I. $(4)$ & Child parenting status \\
\hline $\begin{array}{l}\text { 23) Are you worried that rearing a child would be too tiresome } \\
\text { because of your husband's poor health? } \\
\text { 15) Will pregnancy and birth be a burden on your physical and mental health? } \\
\text { 13) Are you concerned that taking medicine/undergoing x-ray examinations during } \\
\text { pregnancy will influence fetal development? }\end{array}$ & J. (3) & $\begin{array}{l}\text { Physical health status of } \\
\text { parents and fetus }\end{array}$ \\
\hline 12) Do you not have enough living space at home? & K. (1) & Re-allocation of living environment \\
\hline 28) Are you concerned about being mocked at for "having a baby at such an old age"? & L. (1) & Sociocultural opinions \\
\hline
\end{tabular}

a. Number in parenthesis denotes the adjusted ranking of the decision criteria based on participants' opinions. b. U represents "Unless"; otherwise, path is modified.

If, however, they already knew that the baby had a high likelihood of being unhealthy, this changed their decisions.

The participants were also affected by their attitude toward death. Those who regarded death as a natural event in life typically demonstrated neutral acceptance toward induced abortion. This accords with the Death Attitude Profile-Revised [11], in that individuals who are neutrally accepting of death view 
death as a natural, undeniable, and unavoidable event. Conversely, termination of pregnancy was more likely among individuals who exhibit death avoidance, that is, those who avoid induced abortion and death, and among those who believe that a 5-week-old fetus during unplanned pregnancy is too small to be considered a living thing.

d) Consideration of mother-in-law, mother or husband's views regarding gender role effects on carrying on the ancestral line

In Chinese society, the traditional belief that only men can continue the family line has prompted women to do their utmost to give birth to boys, or bring an adequate number of boys to the family. Some of these women opt for induced abortion when they have met these requirements. Not only their mothers-in-law and the husband's side of family, but their own mothers will worry about their position within the husband's family and thus encourage them to give birth to baby boys, in order to receive better treatment. The attitude of these women's husbands, who are stuck in the middle, also somewhat influences decisions regarding unplanned pregnancy. In addition, a now-compliant, now-badmouthing situation can easily create tension within the marital relationship.

e) Significance of number of children, gender, and appearance

When already satisfied with the gender or number of their children, most of the participants would consider receiving an induced abortion rather than having the baby. An increasing number of parents want only one child, or even none; and as a result, many will consider induced abortion. Women who have given birth two or more times will pay particular attention to the number of children they have. If their pregnancies are unplanned but the number of children would be acceptable, these women will change their original intention of not having children, in order to see the face of their first child. Some women consider continuing a second pregnancy, because they wish to give their existing child a sibling.

f) Economic burdens

Participants would terminate their pregnancies if they felt that the child would increase their financial burden, such as basic living expenses (food, clothing, accommodations, and travel, or mortgage loans) or other expenditures (e.g., supporting their parents, or the considerable amount of money needed for the upbringing of their children).

g) Work, career, and time management

Working women make trade-offs between work and having a baby when they are busy with work, being exhausted both physically and mentally, or requiring more time in adjusting to changes at work and other challenges. These women tend to take work and their financial capability into consideration first, especially once they have reached the preferred number and genders of children.

h) Impression of and influence by previous pregnancies

The emotions and memories associated with giving birth or induced abortion influenced the participants' decisions to either receive induced abortion (surgically or via RU486 approach) or to continue their pregnancy. 
i) Child parenting status

For adult married women who have experienced unplanned pregnancy and induced abortion more than twice, they would take into consideration their state of health, lifestyle, physical strength, workload, child rearing practices, family and married life, and whether or not they were fully psychologically prepared. In particular, state of health and physical strength were criteria influencing the decision to give birth to the child or not. They not only considered the process of pregnancy and giving birth; childcare and education problems after birth are even more important [12]. For instance, for long-distance couples or those with different schedules, the loneliness of assuming child-rearing responsibilities alone, the lack of balance, and the stress can influence childbirth decisions and how couples feel for each other. Whether or not to have another baby was also influenced by age (women over 40 years of age would consider not having another child because of their age), distribution of care resources for any existing children, and inability to care for and educate the child.

j) Physical health status of parents and fetus during birth

The participants would not consider keeping the baby when they were concerned about the potential health effects of pregnancy on the mother or baby, including effects of drug or alcohol use during early pregnancy on the fetus' health, or one partner was too busy with a physical condition for another unplanned pregnancy. Even if the doctors had confirmed that there were no threats to the health of the baby (e.g., flu medication or X-ray), adult married women would still choose induced abortion to avoid having to bear the heavy burden or consequences of an unhealthy baby.

k) Re-allocation of the living environment

Financial and child-rearing resources must be re-allocated whenever a new child is born, particularly. The need to change to a new living situation, in particular, tends to put these women off from having another child.

1) Sociocultural opinions

The participants would terminate their pregnancies when they felt ashamed and guilty for being pregnant at the age of 40 years or more [7], or when they felt embarrassed for having more than three children already.

2) Decision Criteria and Characteristics

Integration of the aforementioned 12 decision criteria yields four types of decision patterns among adult married women with unplanned pregnancies:

a) Decisively opting for induced abortion

When worried that drugs or x-rays would influence the baby's health, most women would decisively opt for induced abortion. Those who had no requirements in addition to the children they already had (e.g., with regard to number or gender); those with heavy workloads or heavy economic burdens; and those who had experienced difficulty in pregnancy or childrearing were more likely to opt decisively for induced abortion.

b) "Since I'm pregnant, I might as well have it" 
Sixteen percent of the adult married women had no intention of having children after getting married; however, when they unexpectedly conceived for the first time, they would think that, since they were already pregnant, they might as well have the baby.

c) Think carefully and don't rush into it: A life-changing decision

Many considerations, such as religious beliefs, relationship with the husband, the feeling of pre-ordination when still having a fetus even after taking a morning-after pill and not originally planning to have a baby, or the belief that an embryo is a living thing, are all factors influencing the final decision regarding pregnancy.

d) The main person responsible for coercion to give birth

When the husband or mother-in-law coerces them into pregnancy or forbids induced abortion in hopes that they will give birth to a baby boy, and when the husband is always the one to have the final say, then whether the woman is to continue her pregnancy or terminate it will still be decided by the husband; this creates tension within the couple's relationship, and causes the woman to feel helpless and without options.

\section{Discussion and Conclusion}

Decisions about unplanned pregnancy-whether to continue or terminate pregnancy-are complex and diverse. They involve family relationships, couples' power structures, child-rearing functions, division of labor at home, allocation of resources in the living environment, and overall sociocultural opinions. The findings of this study regarding the 12 main decision characteristics and the associated decision criteria can shed light on what dimensions of their situations others take into consideration when making decisions about unplanned pregnancies. The results of this study revealed that most of the participants were inclined to undergo an induced abortion when their pregnancy was unplanned; their relationship with the other half was unstable; they could not afford to have another child; they did not have time or did not have enough space at home; they had had previous bad experiences with pregnancy or childcare; or when they were concerned about the health of the father, themselves, or the baby. Adult married women generally decided to continue with their unplanned pregnancy when they believed that a fetus is a living thing; or when they had taken into consideration the opinions of their mother-in-law/biological mother/ husband regarding the number, gender, and appearance of children. Some factors for consideration and ranking should still be re-examined and modified, and the subsequent results should be able to provide a reference for improving the declining birth rate situation in Taiwan.

1) Other family members influence pregnancy decisions

Demands from mothers-in-law/mothers to continue the family line are the first consideration senior women take when pregnant, and this factor of consideration influences degree of satisfaction toward the gender and number of 
children in the family. Yet when the new generation of couples insists on not having children, the resulting generational conflicts increase the perplexity of the decision-making process. However, such demands are rare nowadays, because some mothers-in-law support their daughters-in-law not having children, to save them from the hardship of giving birth and caring for another child; whereas sometimes it is actually their own mothers who urge daughter to give birth to a boy, for fear that not having a boy might influence her status in the husband's family.

In this study, $51 \%$ of the participants' husbands disapproved of the need to carry unplanned pregnancies to term and care for the resulting children; and they did not insist on the need to have a boy in the family. And from an economic standpoint, husbands would rather choose to terminate an unplanned pregnancy to avoid increasing their financial burden, and so they support their wives in responding to criticisms or even in persuading their wives to terminate the pregnancies. For women, in the role of mother, they would consider whether their current child(ren) can accept having a younger sibling, or whether the family is able to bear the economic burden of having a boy and girl in the family. Subsequently, they would choose to undergo induced abortion for the sake of controlling the family's economic burdens.

2) Unplanned pregnancy is considered when family resources for raising children are adequate and chores are evenly divided

Parents typically devote all their attention and money in bringing up their children, hoping that they will become outstanding adults. They will decide whether or not to keep an unplanned pregnancy based on considerations such as whether or not the child is able to receive adequate educational support in an economically stable environment. Specifically for women who would not resign from committing to care for their child themselves to ensure proper development, they would be concerned about whether their children would be able to become a good person under limited care, and eventually decide against continuing an unplanned pregnancy. This phenomenon is particularly prominent among women living in metropolitan areas (such as Taipei, the subject of this report) who believe that their children must be brought up to be the best.

In addition, rearing a child together and sharing responsibilities at home are core issues of interest for couples in contemporary society [13]. Dual-earner couples are likely to have discontent with each other from sharing household responsibilities, thus influencing the family relationship and discouraging women from having another child.

3) Equal marital power decides birth but not necessarily cooperative pregnancy

Tsai [14] asserted that whoever holds more resources in a marriage has greater power. Relationships based on the survival of the fittest influence the stability of the feelings the participants in this study had with their partners; and this is also one of the reasons why they continued with pregnancy or chose induced abortion. A majority of the women still felt that, after all, they are the ones carrying the child and the ones enduring the pain. These women typically have conflicts 
with their husband from fighting over parental control rights when they are confronted with the forced intervention of their husbands, dissenting opinions, or when they held onto the decision to continue or terminate the pregnancy. In some instances, some women would accede to their husband's decision or surrender to his power, for fear that their decision would not be supported, thus causing greater conflict. Such imbalance of power inflicts feelings of helplessness and loss, thus endangering the couple's relationship.

4) An unsuited living environment or pregnancy at an advanced age discourages pregnancy

In consideration of the influence of a living environment on children and the family; the need and the money required to move away from a place they have grown accustomed to; and the peculiar sociocultural attitudes or ridicule regarding pregnancy after age 35 or having two or more pregnancies, participants were inclined to terminate unplanned pregnancy. This is unless they were desperate to have a son, also a critical factor influencing decisions about unplanned pregnancy; in this case, they would make a choice to do something that goes against the general social mainstream.

\section{Limitation and Application}

In consideration of the limitation of the study, we did not use our multiple decision criteria to draw out a real tree with some paths to make decision. And we did not use these decision criteria to help women to figure out their decision about unplanned pregnancy. However, a "tree structure" decision tree can be used to help women and her families to know other people how to choose alternatives and their directions of a choice. So checking multiple decision criteria of unplanned pregnancy of other people could be used to help them to make decision.

\section{Acknowledgements}

Thanks for the Budget Subsidy (104ntunhs-TR-04) of National Taipei University of Nursing and Health Sciences, and Budget Subsidy (MOST105-2410-H-227-001) from Ministry of Science and Technology in Taiwan.

\section{References}

[1] Gladwin, C.H. (1989) Ethnographic Decision Tree Modeling. Sage, Beverly Hill, CA. https://doi.org/10.4135/9781412984102

[2] Sarafino, E.P. (1994/1997) Health Psychology: Biopsychosocial Interactions. Lauréat Publications, Taipei.

[3] Morgan, P., Saucer, C. and Torg, E. (1996/2003) The Female Body. Taiwan Mac group, Taipei.

[4] Kenneedy, K. and Insel, P. (2000) What's New in Contraception?-Understanding the Options. Healthline, 6-8.

[5] Mertus, J., Flowers, N. and Dutt, M. (2004) Local Action Global Change: Learning about the Human Rights of Women and Girls. 
http://www.cwgl.rutgers.edu/docman/coalition-building-publications/363-localacti onglobalchange-pdf/file

[6] Chinatimes (19 August 2004) “3321” Let You Have Happiness. http://homepage.ntu.edu.tw/ psc/pop_news9308/081901.htm

[7] Li, H.J. and Chen, Y.L. (2003) The Lived Experiences of Married Women Who Request Early Medical Abortion with RU486 (Mifepristone). The Journal of Nursing, 50, 50-58.

[8] Chinatimes (19 August 1999) Everyday Is “Abortion Day”: Generation Y, a Generation Which Indulge in Youthhood. http://sex.ncu.edu.tw/blognews/?p=2923

[9] Taiwan Women Web (1998) The Situation of Taiwan Women. http://taiwan.yam.org.tw/womenweb/st_health.htm

[10] Huang, H.L. and Yeh, M.C. (2006) Introduction to Ethnographic Decision Tree Modeling. The Journal of Nursing, 53, 60-68.

[11] Wong, P.T.P., Reker, G.T. and Gesser, G. (1994) Death Attitude Profile-Revised: A Multidimensional Measure of Attitude toward Death. In: Neimeyer, R.A., Eds., Death Anxiety Handbook: Research, Instrumentation, and Application, Taylor \& Francis, IH, 121-148.

[12] Huang, H.R. (2007) Mature Men and Women Are Hard to Have Children. http://www.commonhealth.com.tw/article/article.action?nid=66856

[13] Papp, P. (2000/2004) Couples on the Fault Line: New Directions for Therapists, Psychological Publishing Co., Ltd., Taipei.

[14] Tsai, W.H. (2003) Marriage and Family. Wu-Nan Book, Inc, Taipei. 